\title{
Percutaneous coronary interventions in Europe 1992-2001
}

\author{
Mario Togni ${ }^{a}$, Florian Balmer ${ }^{a}$, Dorothy Pfiffner ${ }^{b}$, Willibald Maier ${ }^{c}$, \\ Andreas M. Zeiher ${ }^{d}$, Bernhard Meier ${ }^{a, *}$, on behalf of the Working Group \\ Interventional Cardiology and Coronary Pathophysiology of the European \\ Society of Cardiology
}

a Department of Cardiology, Swiss Cardiovascular Center Bern, University Hospital, 3010 Bern, Switzerland

b Kantonale Ethikkommission Bern, Med. Fakultat der Universitat Bern, Bern, Switzerland

c Department of Cardiology, University Hospital Zurich, Zurich, Switzerland

d J. W. Goethe Universität Frankfurt, Med. Klinik IV - Kardiologie, Frankfurt, Germany

Received 21 January 2004; revised 31 March 2004; accepted 13 April 2004

Available online 2 July 2004

\author{
KEYWORDS \\ Coronary angiography; \\ PTCA; \\ $\mathrm{PCl}$; \\ Coronary interventions; \\ Coronary stent; \\ Registry
}

\begin{abstract}
Aims The purpose of this registry is to collect data on trends in interventional cardiology within Europe. Special interest focuses on relative increases and ratios in newer re-vascularisation approaches and its distribution in different regions in Europe. We report the data of the year 2001 and give an overview of the development of coronary interventions since 1992, when the first data collection was performed. Methods and Results Questionnaires were distributed to delegates of the individual national societies of cardiology represented in the European Society of Cardiology. These were completed by the local institutions and operators and showed that $1,806,238$ angiograms and 617,176 percutaneous transluminal coronary angioplasties (PTCAs) were performed in 2001. This is an increase of $10 \%$ and $17 \%$, respectively, compared with the year 2000. The population-adjusted PTCA rate rose from nearly 800 procedures per $10^{6}$ inhabitants in the year 2000 to approximately 990 procedures per $10^{6}$ inhabitants in 2001 . Coronary stenting increased by $25 \%$ to about 488,900 stents implanted in 2001. Complication rates remained unchanged, and the need for emergency coronary artery bypass grafting is still at $0.2 \%$ per percutaneous intervention.

Conclusion Interventional cardiology in Europe is still expanding, mainly due to rapid growth in countries with lower socio-economical levels. Most central European countries reported only minor increases in procedures performed. Coronary stenting remains the only noteworthy adjunctive strategy to balloon angioplasty.

(c) 2004 The European Society of Cardiology. Published by Elsevier Ltd. All rights reserved.
\end{abstract}

\section{Introduction}

Little reliable data exist which provides field trends in interventional cardiology. ${ }^{1-4}$ The report on Interventional Cardiology in Europe in 2001 provides the 10th edition of yearly reports initiated in $1992 .^{5-13}$ The aim
Corresponding author. Tel.: +41-31-632-3077; Fax: +41-31-382-1069.

E-mail address: benhard.meier@insel.ch (B. Meier). 
of this report is to show trends in cardiac catheter interventions in Europe over the last 10 years. It summarises cardiac catheter interventions and gives an overview of specific interventional cardiological activities in 29 countries of Europe, the majority of the members of the European Society of Cardiology.

\section{Methods}

A detailed questionnaire, together with instructions and examples for completion, was sent to the presidents or designated delegates of the national societies of cardiology represented in the European Society of Cardiology. It was distributed nationwide to all facilities performing diagnostic or interventional cardiac catheterisation. A summary data sheet, filled out by the national representatives, was used to report the nationwide data set. Finally the data were entered into the central database and analysed. In the case of missing or incomplete data, the national representatives were repeatedly reminded. In September 2003, the registry was closed for the 2001 report. Sufficient data were reported from 29 of the 32 countries included in the survey, representing more than 550 million people. Despite numerous reminders Bulgaria, Ireland, Morocco did not provide sufficient data to be included in the survey. Prior to publication, the manuscript was submitted to the country representatives to have the figures checked for accuracy. Definitions of pathologies and procedures, as well as questionnaires, were used according to previously published reports. ${ }^{8}$

\section{Results}

\section{Coronary angiography}

Of the 32 distributed country summaries, 29 were received and analysed. A total of $1,806,238$ coronary angiograms were performed in Europe in 2001 (Fig. 1). This corresponds to an increase of $10 \%$ compared with 2000. In the 10-year period from 1992 to 2001 a 3-fold increase of coronary angiograms occurred. In 2001, Germany reported the highest absolute and relative numbers, namely 611,882 angiograms or 7462 per million inhabitants (Fig. 2). This is a relative increase of $2 \%$ compared with 2000. Other central European countries reported varying increases in population-adjusted angiograms performed: Finland $+30 \%$, Austria $+9 \%$, Italy $+8 \%$, United Kingdom $+4 \%$, Norway $+3 \%$, Switzerland $+0.5 \%$. Most of the eastern European countries showed increases in angiograms per population. Poland reported the highest rise with 34\%, while Slovakia and Latvia were the only countries with a decrease of $-4 \%$ and $-5 \%$, respectively.

\section{Coronary angioplasty}

A total of 617,176 percutaneous transluminal coronary angioplasty (PTCA) procedures were reported for 2001, a $17 \%$ increase compared with 2000 (Fig. 1). Compared with the annual yearly survey in 1992 this constitutes a

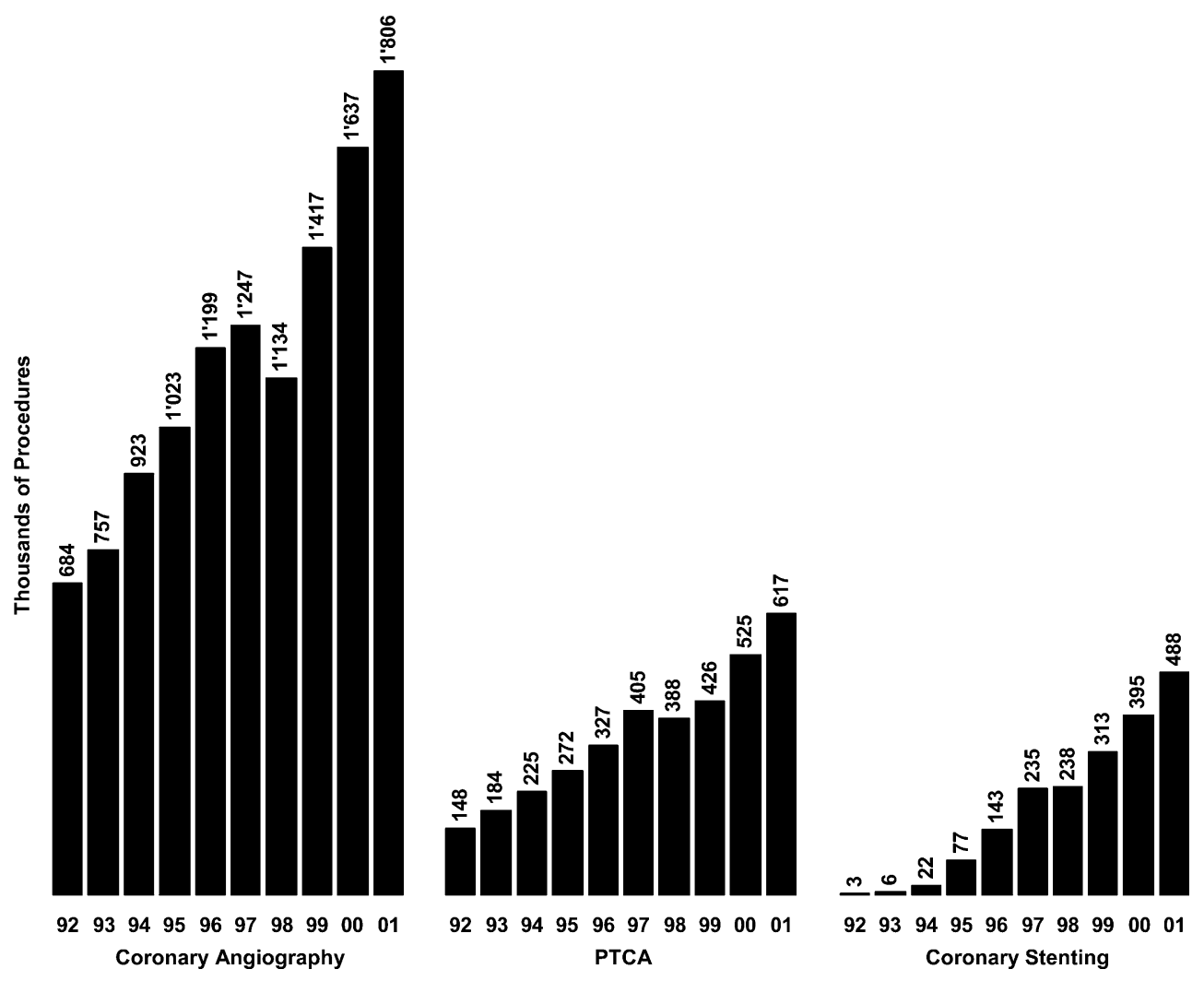

Fig. 1 Coronary angiograms, coronary angioplasty (PTCA), and coronary stenting from 1992 to 2001 in Europe in thousands of procedures. 

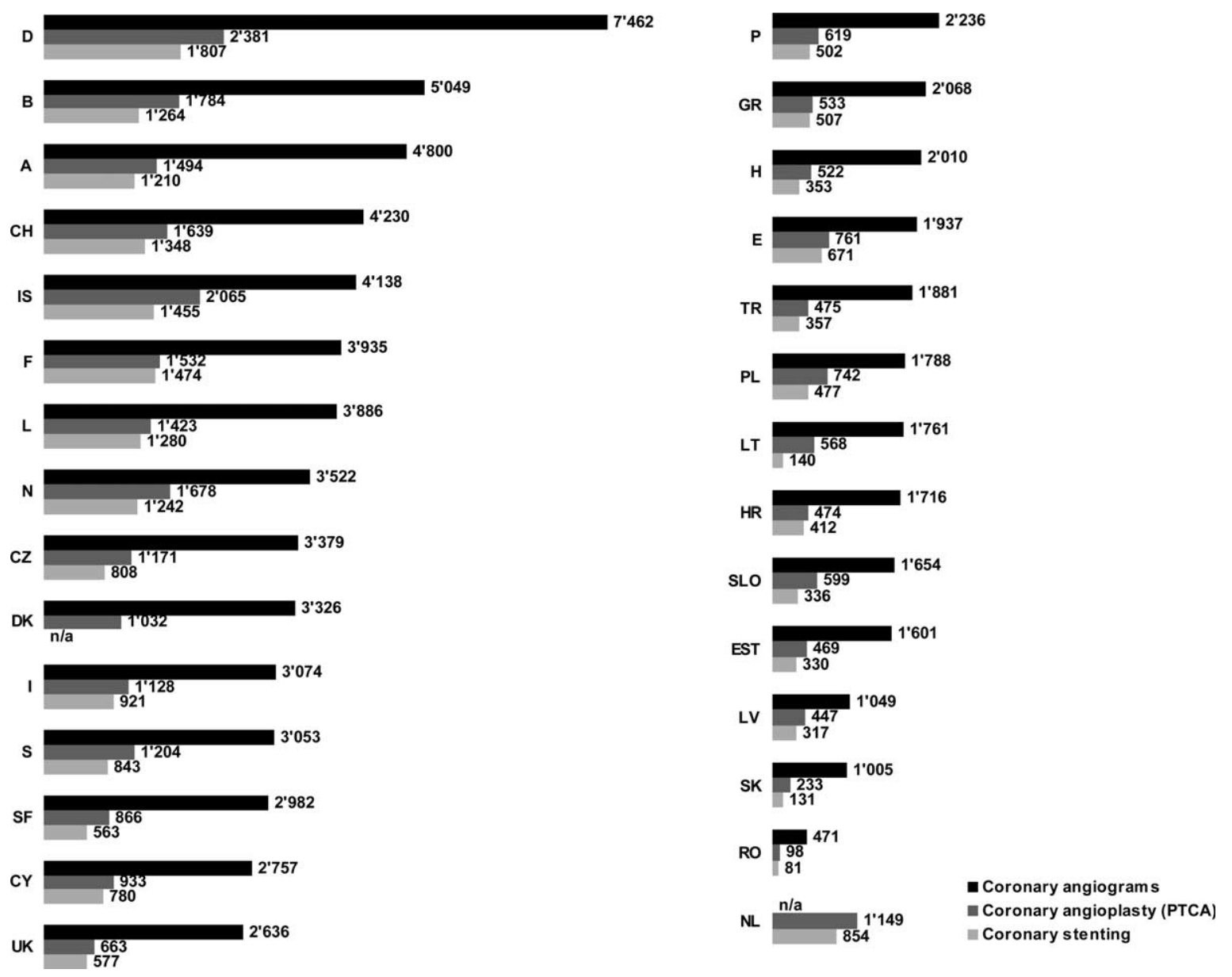

Fig. 2 Coronary angiograms, coronary angioplasty (PTCA), and coronary stenting per $10^{6}$ inhabitants and country in 2001. A, Austria; B, Belgium; CH, Switzerland; CY, Cyprus; CZ, Czech Republic; D, Germany; DK, Denmark; E, Spain; EST, Estonia; F, France; GR, Greece; H, Hungary; HR, Croatia; I, Italy; IS, Iceland; L, Luxembourg; LT, Lithuania; LV, Latvia; N, Norway; NL, Netherlands; P, Portugal; PL, Poland; RO, Romania; S, Sweden; SF, Finland; SK, Slovak Republic; SLO, Slovenia; TR, Turkey; UK, United Kingdom.

5 -fold increase in percutaneous procedures. The mean population-adjusted number in 2001 was nearly 990 procedures per $10^{6}$ inhabitants, representing an increase of $24 \%$ compared with the year 2000 (about 800 PTCAs per $10^{6}$ inhabitants). Germany reported 195,280 PTCAs or 2381 PTCAs per $10^{6}$ inhabitants, by far the highest numbers (Fig. 2). Iceland was the only country with a population-adjusted PTCA rate comparable with Germany with 2065 procedures per $10^{6}$ inhabitants. The smallest numbers of procedures per million people were reported from Romania (98) and Slovakia (233). All countries reported relative increases in procedures. There is however an enormous variability with eastern European countries reporting the highest relative increase (Hungary $+108 \%$, Poland $+53 \%$ ).

The mean ratio of PTCAs to coronary angiograms was 0.33 (2000: 0.32 ). The ratio of PTCAs to coronary angiograms ranged from 0.21 in Romania to 0.50 in Iceland (Fig. 3). Ad hoc PTCA procedure rate reached a share of $52 \%$ and the highest ad hoc percentages were reported from Cyprus (84\%), followed by Luxembourg (76\%), Slovenia (76\%), and Estonia (75\%). From 1992 to 2001 the share of ad hoc PTCA procedures increased from about $25 \%$ to $52 \%$ (Fig. 4 ).
Multi-vessel interventions in one session were performed in $18 \%$ in 2001 . In the 10-year period there is no clear trend towards a relative increase in multi-vessel procedures. Interventions for acute myocardial infarction in 2001 amounted to $15 \%$ of all coronary procedures. These numbers are comparable with those reported by the National Cardiovascular Data Registry of the American College of Cardiology for 1998 to $2000 .^{3}$ The 10 -year overview shows an increase of interventions for acute myocardial infarction per PTCA from $4 \%$ to $15 \%$ (Fig. 5).

\section{Coronary stenting}

Approximately 488,900 stenting procedures were reported in 2001 (Fig. 1), resulting in an increase of 25\% compared with 2000 (approximately 395,000 procedures). Stenting was rare in 1992 with a total of 3211 procedures (six per million) but these procedures tripled from 1993 to 1994, and quadrupled from 1994 to 1995. Since 1996 stenting procedures have shown a mean annual increase of $38 \%$ and Germany and France reported the highest absolute numbers for 2001 with 148,157 and 88,424 , respectively. The ratio of coronary stenting to PTCA procedures averaged 0.75 most countries reporting 


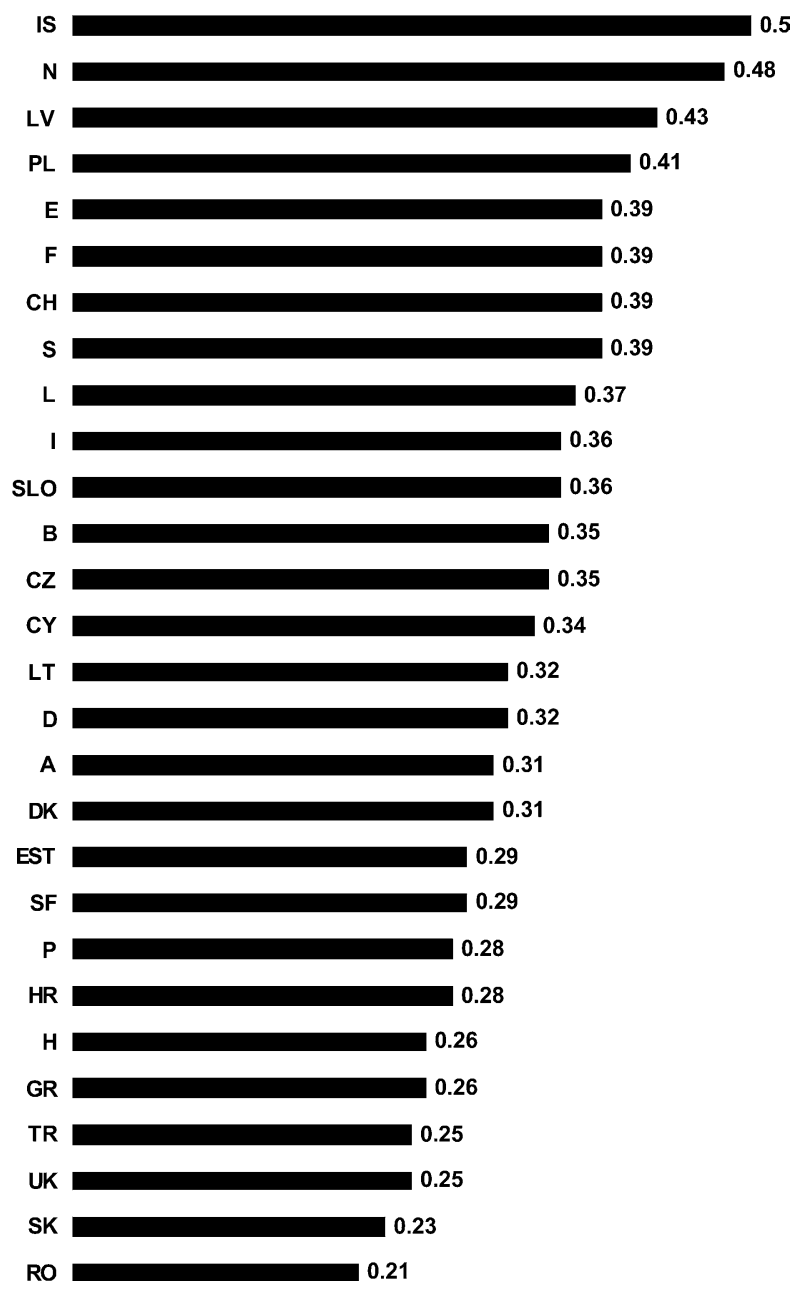

Fig. 3 PTCAs per coronary angiogram ratio in 2001 in Europe (abbreviations as in Fig. 2).

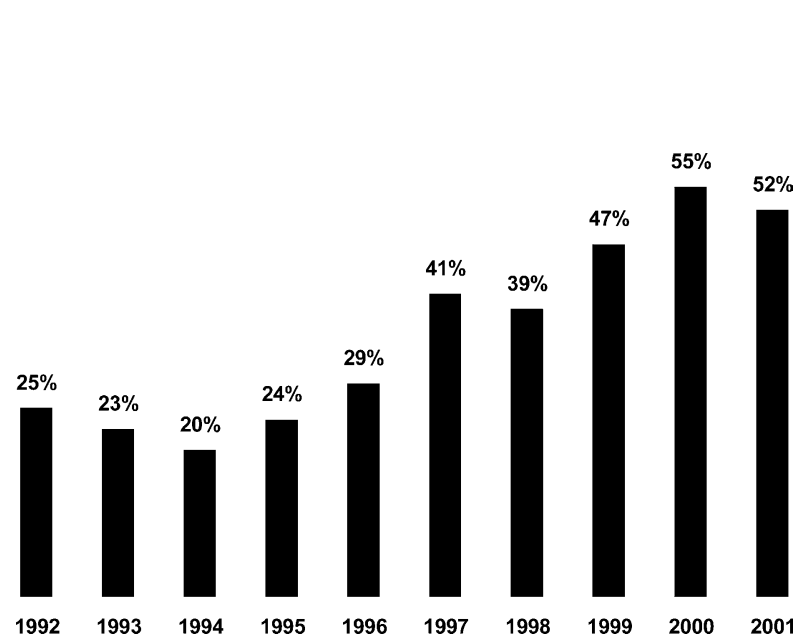

Fig. 4 Ad hoc PTCA rate from 1992 to 2001 in Europe.

ratios of 0.70 or above (Fig. 6). Drug-eluting stents were introduced in 2001 but no systematically collected data on their use in 2001 is available.

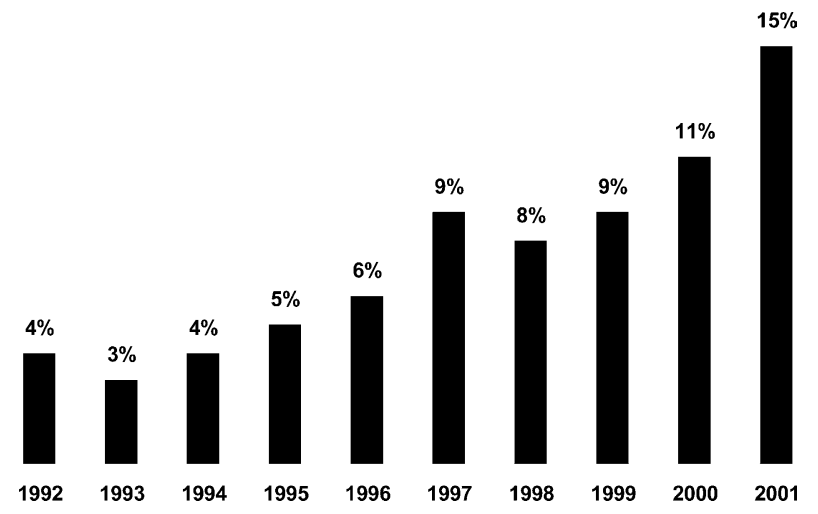

Fig. 5 PTCA rate for acute myocardial infarction from 1992 to 2001 in Europe.

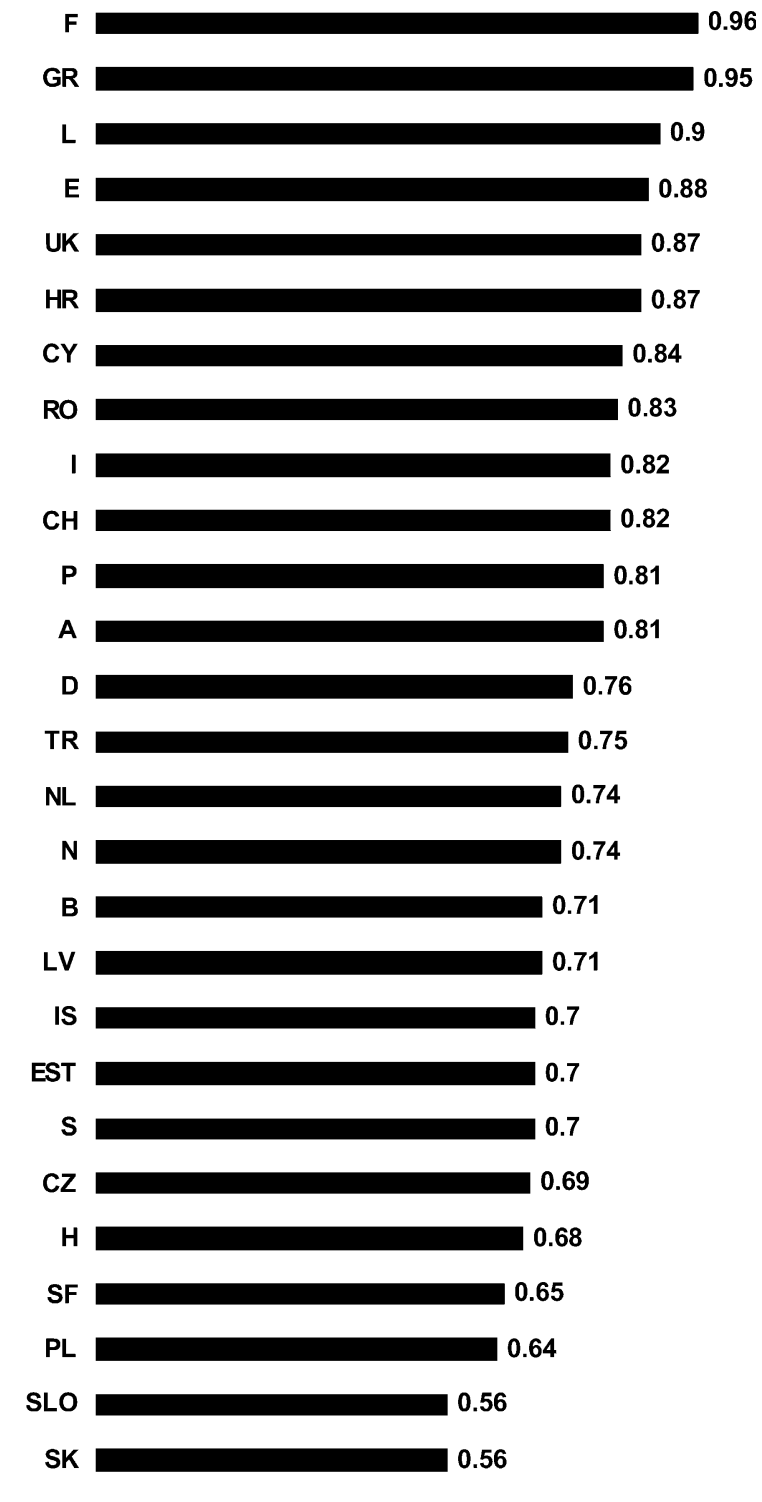

LT 0.25

Fig. 6 Coronary stenting per PTCA ratio and country in 2001 (abbreviations as in Fig. 2). 


\section{Other devices}

Other therapeutic devices (directional atherectomy, rotablator, laser or wire catheter, ultrasound therapy, brachytherapy, cloth catcher/remover) were reported in a total of 11,416 cases in 2001 . There were no sweeping changes over the last 10 years, and none of the devices reached the $1 \%$ level.

\section{Complications}

Myocardial infarction was reported in $1.1 \%$ and death in $0.6 \%$. These rates have not changed over the last 10 years, and are in accordance with data from American registries. ${ }^{3,4}$ The need for emergency CABG remained unchanged at $0.2 \%$. This reflects a 10 -fold reduction of the relative need for emergency CABG during the last 10 years (Fig. 7).

\section{Catheterisation facilities}

According to the reported numbers, there was a mean of 2.5 cardiac catheterisation facilities per $10^{6}$ inhabitants in Europe. In the previous year, there were 2.8 with the highest density existing in Iceland $\left(7.3\right.$ per $\left.10^{6}\right)$ and the lowest in Romania (0.35 per $\left.10^{6}\right)$. A mean of 1019 (565-1852) diagnostic procedures per catheterisation room and 325 angioplasties (188-519) per catheterisation room were performed. The number of diagnostic operators per million people ranged between 2 in Romania and 44 in Iceland, and the coverage with $\mathrm{PCl}$ operators per million people ranged from 1 in Romania to 16 in Switzerland.

\section{Discussion}

The Interventional Cardiology and Coronary Pathophysiology working group of the European Society of Cardiology has been conducting an annual survey of cardiac interventions since 1992. ${ }^{5-13}$ This report summarises the data reported for 2001 and shows the development of interventional cardiology in Europe from 1992 to 2001. Sufficient data for the year 2001 were reported from 29 countries, representing 550 million people in Europe. The information provided by the national societies of cardiology was voluntary and not scrutinised and no audit or quality control was performed. Therefore, the data are aggregated, retrospective and under-reporting of complications is very likely.

In 2001, a total of 1,806,238 diagnostic procedures and 617,176 PTCAs were reported, corresponding to an increase of $10 \%$ and $17 \%$, respectively, compared with the year 2000. The proportional rise in PTCA procedures was slightly higher than the rise in angiographies resulting in a rise of the PTCA to coronary angiography ratio from 0.32 in 2000 to 0.33 in 2001 . The angiography numbers are still increasing throughout the European community. For the PTCA procedures there is a marked difference between the different nations, with eastern European countries reporting the highest increases. The only northern and central European countries reporting high rises in PTCA procedure-rates are Norway and Spain $(+34 \%$ and $+31 \%$, respectively). Spain has lagged behind the other western European countries in the past years but it is probable that this country is reaching rates comparable to countries with similar gross national products.

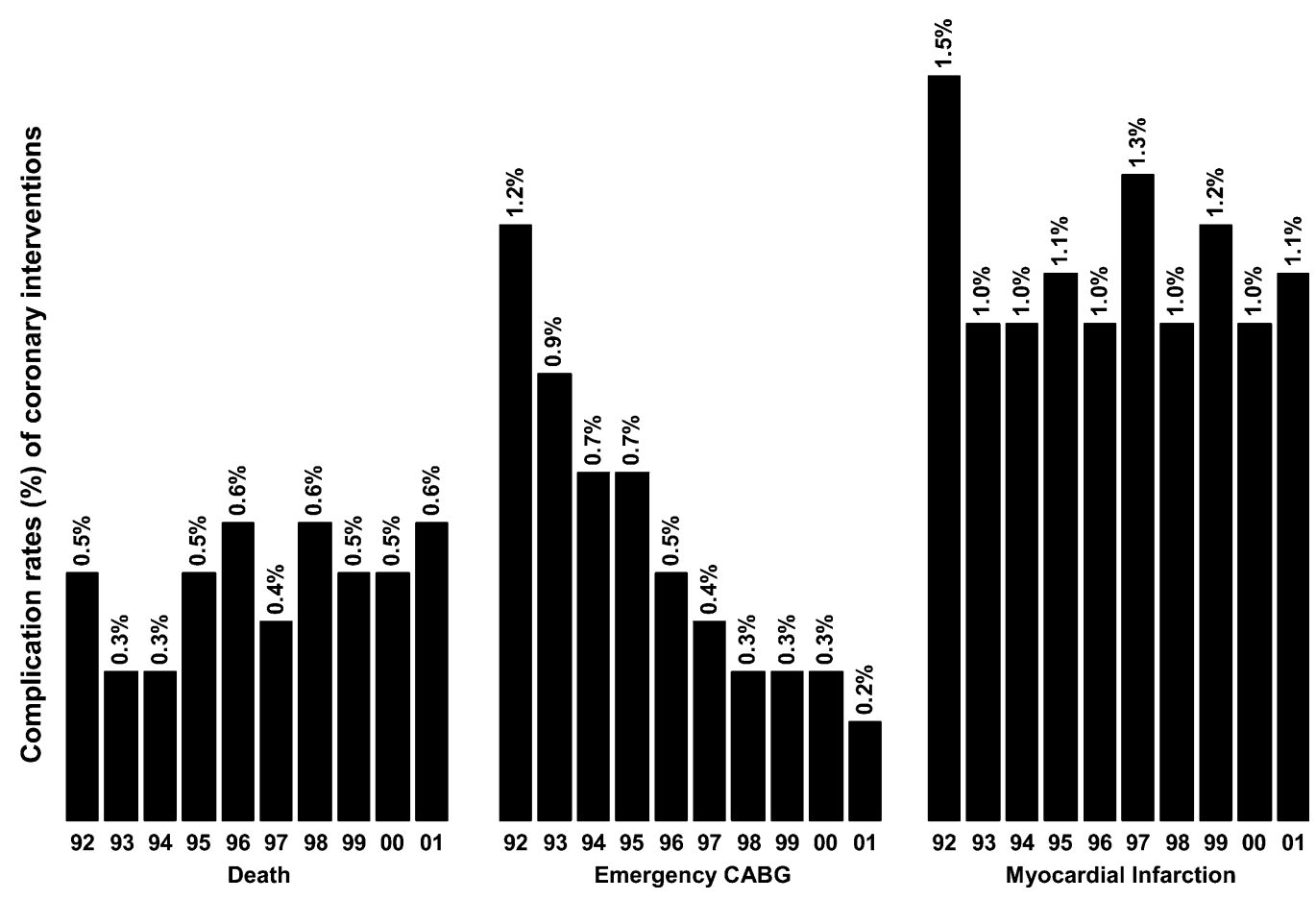

Fig. 7 Complication rates (\%) of coronary interventions from 1992 to 2001 in Europe. 
The ad hoc PTCA procedure rate appears to have reached a plateau. This is surprising considering the change in attitude to the technique by both physicians and patients. Logistical, and perhaps political, reasons must account for the slow progress of the logical combination of diagnostic and therapeutic catheterisation. Some countries had passed the $80 \%$ level already the years ago.

The percentage of multi-vessel PTCAs was 18\%. Multivessel PTCA rate has shown a slight increase during the past years. This is in contrast with the general opinion that the introduction of stents has led to a substantial increase in multi-vessel PTCAs. The percentage of staged multi-vessel procedures is not known. It will be interesting to observe the impact of drug-eluting stents on multi-vessel PTCAs. ${ }^{14}$

Major complication rates for PTCA have remained unchanged and the need for emergency CABG has further declined. As pointed out previously, under-reporting of complications is very likely due to the missing audit and quality control.

It is encouraging to see the percentage of interventions for acute myocardial infarction rise to $15 \%$. This might reflect the assimilation of the results of the PRAGUE, PRAGUE-2 and DANAMI-2 trials, ${ }^{15-17}$ which favoured primary angioplasty over thrombolysis for acute myocardial infarction, even when transportation to a tertiary angioplasty centre is necessary. This trend is likely to continue over the next years.

The reported number of coronary stenting procedures showed an increase of $25 \%$ from 391,000 in 2000 to 488,900 in 2001 . Coronary stents were applied in $72 \%$ of coronary angioplasties. Central and western European countries used more stents, and their stenting rate went as high as $96 \%$ in France. Each country included in the survey reported an increase in the use of stents from 2000 to 2001.

In 2001, drug-eluting stents have been used only sporadically. It remains to be seen if this new device will have any impact on the overall numbers of procedures in the next year or whether it has a greater impact on the number of complex cases. ${ }^{18}$

\section{Appendix}

We express our thanks to all representatives of the national societies of cardiology and the local persons put in charge in the individual centres for their highly appreciated help with this data collection. Following an alphabetical list of the principal data coordinators of each country that participated in this survey:

Austria: Mühlberger V. Belgium: Heyndrickx G. Croatia: Mihatov S. Cyprus: Zambartas C. Czech Republic: Vojacek J. Denmark: Thayssen P. Germany: Mannebach H. Spain: Hernández JM. Estonia: Peeba L. Finland: Ropponen L. France: Lablanche JM. Greece: Lazaris E.
Hungary: Pasztelyi Z. Iceland: Eyjolfsson K. Italy: Piscione F. Latvia: Erglis A. Lithuania: Navickas R. Luxembourg: Beissel J. Netherlands: Suttorp MJ. Norway: Melberg T. Poland: Witkowski A. Portugal: Gonçalves M. Romania: Capalneanu R. Switzerland: Eeckhout E. Slovakia: Fridrich V. Slovenia: Cijan A. Sweden: Nilsson T. Turkey: Özmen F. United Kingdom: De Belder MA.

\section{References}

1. Unger F, Ghosh P. Cardiac interventions in Europe 2000: surgery and percutaneous procedures. European Heart Institute; 2002.

2. Ruygrok PN, Ormiston JA, O'Shaughnessy B. Coronary angioplasty in New Zealand 1995-1998: a report from the National Coronary Angioplasty Registry. N Z Med J 2000;113:381-4.

3. Laskey WK, Kimmel S, Krone RJ. Contemporary trends in coronary intervention: a report from the Registry of the Society for Cardiac Angiography and Interventions. Catheter Cardiovasc Interv 2000;49:19-22.

4. Anderson HV, Shaw RE, Brindis RE et al. A contemporary overview of percutaneous coronary interventions. The American College of Cardiology - National Cardiovascular Data Registry (ACC-NCDR). J Am Coll Cardiol 2002;39:1096-103.

5. Roethlisberger C, Meier B. Coronary interventions in Europe 1992. The Working Group on Coronary Circulation of the European Society of Cardiology. Eur Heart J 1995;16:922-9.

6. Meyer BJ, Meier B, Bonzel T et al. Interventional cardiology in Europe 1993. Working Group on Coronary Circulation of the European Society of Cardiology. Eur Heart J 1996;17:1318-28.

7. Windecker S, Meyer BJ, Bonzel T et al. Interventional cardiology in Europe 1994. Working Group Coronary Circulation of the European Society of Cardiology. Eur Heart J 1998;19:40-54.

8. Windecker S, Maier-Rudolph W, Bonzel $\mathrm{T}$ et al. Interventional cardiology in Europe 1995. Working Group Coronary Circulation of the European Society of Cardiology. Eur Heart J 1999;20:484-95.

9. Maier W, Windecker S, Lablanche JM et al. The European registry of cardiac catheter interventions 1996. Eur Heart $J$ 2001;22:373-7.

10. Maier W, Camici P, Windecker $S$ et al. The European registry of cardiac catheter interventions 1997. Eur Heart J 2002;22:1903-7.

11. Maier $W$ et al. The European Registry of Cardiac Catheter Interventions 1998. J Kardiol 2004;11:145-8.

12. Rotter $M$, Pfiffner $D$, Maier $W$ et al. Interventional cardiology in Europe 1999. Eur Heart J 2003;24:1164-70.

13. Balmer F, Rotter M, Togni M et al. Interventional Cardiology in Europe 2000. Int J Cardiol (in press).

14. Serruys PW, Unger F, Sousa JE et al. Comparison of coronary-artery bypass surgery and stenting for the treatment of multivessel disease. N Engl J Med 2001;334:1117-24.

15. Widimsky $P$, Groch L, Zelizko $M$ et al. Multicentre randomized trial comparing transport to primary angioplasty vs immediate thrombolysis vs combined strategy for patients with acute myocardial infarction presenting to a community hospital without a catheterization laboratory. The PRAGUE study. Eur Heart J 2000;21:823-31.

16. Widimsky $P$, Budesinsky $T$, Vorac $D$ et al. Long distance transport for primary angioplasty vs immediate thrombolysis in acute myocardial infarction. Final results of the randomized national multicentre trial - PRAGUE-2. Eur Heart J 2003;24:94-104.

17. Andersen HR, Nielsen TT, Rasmussen $\mathrm{K}$ et al. A comparison of coronary angioplasty with fibrinolytic therapy in acute myocardial infarction. N Engl J Med 2003;349:733-42.

18. Lemos PA, Hoye A, Goedhart D et al. Clinical, angiographic, and procedural predictors of angiographic restenosis after sirolimuseluting stent implantation in complex patients. An evaluation from the rapamycin-eluting stent evaluated at Rotterdam Cardiology Hospital (RESEARCH) Study. Circulation 2004;109:1089-94. 